\title{
Barriers to Uptake of Insulin Technologies and Novel Solutions
}

\author{
Meghan E Pauley (D) \\ Cari Berget (iD) \\ Laurel H Messer (DD \\ Gregory P Forlenza (iD) \\ Barbara Davis Center for Childhood \\ Diabetes, University of Colorado \\ Anschutz Medical Campus, Aurora, \\ CO, USA
}

Correspondence: Gregory P Forlenza Barbara Davis Center for Childhood Diabetes, University of Colorado

Anschutz Medical Campus, 1775 Aurora

CT, MS AI40, Aurora, CO, 80045, USA

Tel + I 303-724-2323

Fax + I 303-724-6779

Email gregory.forlenza@cuanschutz.edu

\begin{abstract}
Diabetes-related technology has undergone great advancement in recent years. These technological devices are more commonly utilized in the type 1 diabetes population, which requires insulin as the primary treatment modality. Available devices include insulin pumps, continuous glucose monitors, and hybrid systems referred to as automated insulin delivery systems or hybrid closed-loop systems, which combine those two devices along with software algorithms to achieve advanced therapeutic capabilities, including automatic modulation of insulin delivery based on sensor-derived glucose levels to minimize abnormal glucose trends. Use of diabetes technology is associated with significant positive health and psychosocial outcomes, yet utilization rates are generally lacking across both adult and pediatric type 1 diabetes populations in the United States and other countries. There are consistent themes in existing barriers to technology uptake reported by individuals with type 1 diabetes or parents of children with type 1 diabetes, including physical burdens associated with wearing the devices, concerns in navigating the technology and the devices' abilities to meet user expectations, high cost, inadequate resources within the healthcare team to support device use, disparities in technology access, and psychosocial barriers. It is important to understand the common barriers to uptake of not only the automated insulin delivery systems but also their component devices (insulin pumps and continuous glucose monitors) to fully support individuals in utilizing these devices and optimizing health benefits. The purpose of this article is to summarize the current automated insulin delivery devices that are available for use in management of type 1 diabetes, review common barriers to uptake of those systems and their component devices, and provide expert opinion on existing and future solutions to identified barriers.
\end{abstract}

Keywords: type 1 diabetes, artificial pancreas, insulin pump, continuous glucose monitor, hybrid closed loop

\section{Introduction}

Technological devices are demonstrating an increasingly significant impact in the management of diabetes, especially for those with type 1 diabetes (T1D). ${ }^{1}$ T1D is characterized by an absolute insulin deficiency and typically occurs secondary to progressive autoimmune destruction of insulin-producing pancreatic $\beta$-cells. ${ }^{2}$ T1D is the most common form of diabetes in the pediatric population and incidence rates have continued to rise over previous decades. ${ }^{3,4}$ As insulin is required for survival, the insulinopenic physiology associated with T1D necessitates treatment with insulin for an individual's entire lifetime. Without sufficient insulin in the blood, glucose is unable to enter cells for use in energy production, resulting in elevated blood glucose levels (hyperglycemia). Chronic hyperglycemia is associated with long-term neurologic, 
microvascular, and macrovascular complications that carry substantial morbidity and mortality. Intensive insulin therapy has been shown to reduce the risk of these complications but has also been shown to increase the risk of low blood glucose levels (hypoglycemia), which may result in acute complications such as decreased neurologic and motor function and seizure. The major goal for T1D treatment is achieving glucose trends within goal range, generally considered to be $70 \mathrm{mg} / \mathrm{dL}-180 \mathrm{mg} / \mathrm{dL}$, and maintaining a hemoglobin A1c (HbAlc) of $7 \%$ or less while minimizing hypoglycemia exposure. ${ }^{5}$ The amount of time per day that glucose values are within goal range is referred to as time in range (TIR). The TIR goal for individuals with TID is $>70 \%$, which is associated with reduced risk of long-term complications. ${ }^{6}$

Commonly utilized insulin formulations include longacting insulins (LAI, also referred to as basal insulins) and rapid-acting insulins (RAI, also referred to as short-acting insulins). When utilized, LAIs are administered once or twice daily in combination with RAIs, which are given multiple times a day, such as with meals and to acutely correct hyperglycemia. Multiple daily injection (MDI) insulin regimens are administered via injection with syringe or insulin pen. Alternatively, an increasing number of patients are utilizing continuous subcutaneous insulin infusion (CSII) devices, ${ }^{1,7}$ commonly referred to as insulin pumps, which deliver insulin continuously via a small cannula inserted into the subcutaneous tissue and adhered to the body with adhesive (Figure 1). This replaces the need for LAI use and allows for bolus dosing (rather than injections) of RAI through the day, such as with meals or to correct hyperglycemia.

Diabetes technologies, including insulin pumps and continuous glucose monitors (CGM), can help persons with diabetes (PwD) improve their overall glycemic control, including meeting goals for TIR and HbAlc, and reducing the risk of hypoglycemia. Insulin pump therapy is associated with reduced $\mathrm{HbA1c}$, as well as reduced glucose variability and reduced hypoglycemia compared to MDI regimens. ${ }^{8-11}$ A CGM consists of an interstitial glucose sensor inserted under the skin by the user, which monitors glucose values continuously and communicates values to a receiver, cell phone, and/or insulin pump (Figure 2). These devices have now become accurate enough to replace glucose fingerstick measurements, ${ }^{12}$ and are associated with reduction in hypoglycemic events and improvement in HbAlc (independent of insulin delivery method) ${ }^{13-16}$ and improved sleep for parents of children with T1D. ${ }^{17}$ Furthermore, use of sensoraugmented insulin pump therapy (SAP), a pump that also serves as the CGM receiver and displays the glucose information on the pump screen, has been shown to have a greater impact on HbA1c and hypoglycemia than use of either device individually, as well as reducing fear of hypoglycemia. ${ }^{16,18}$ The most advanced technologies available to date for management of T1D are automated insulin delivery (AID) systems. These systems combine an insulin pump and CGM and contain a software algorithm that uses CGM glucose data to calculate insulin delivery, aiming to

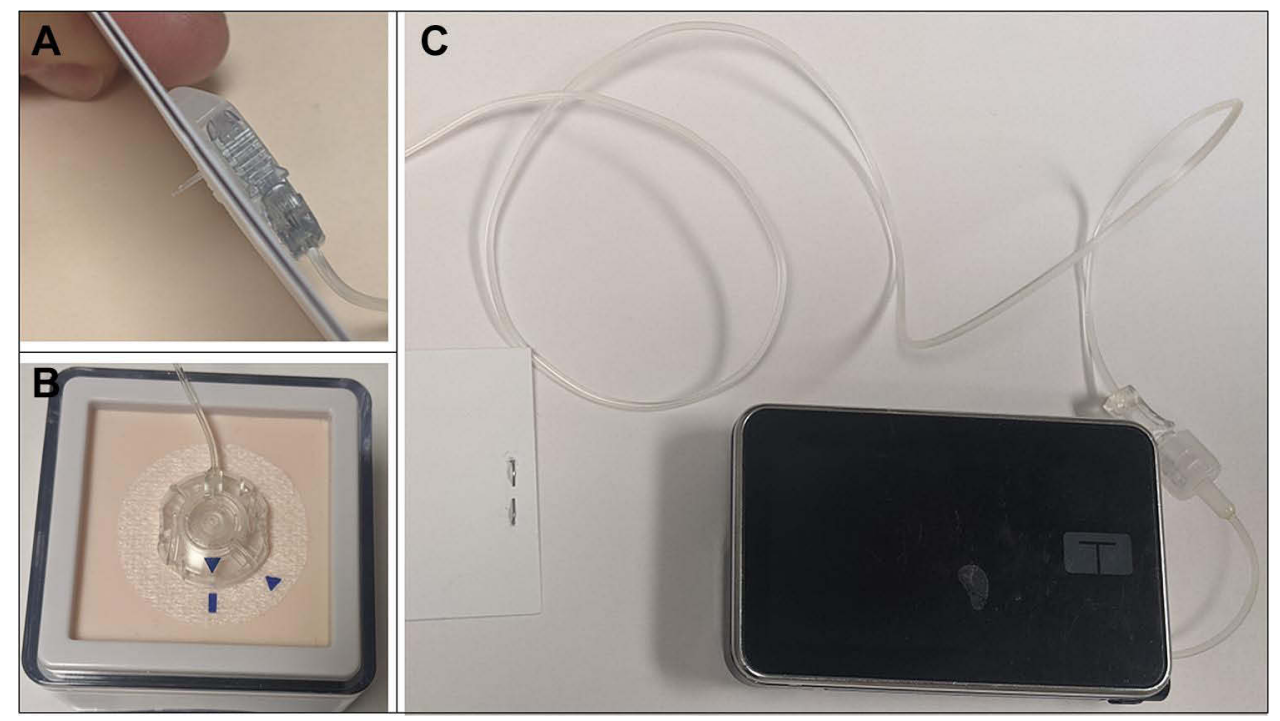

Figure I Example of a tubed CSII pump with infusion set: (A) Subcutaneous infusion set cannula, (B) Detachable subcutaneous infusion set with tubing, (C) Tandem t:slim $\mathrm{X} 2$ insulin pump with tubing. 


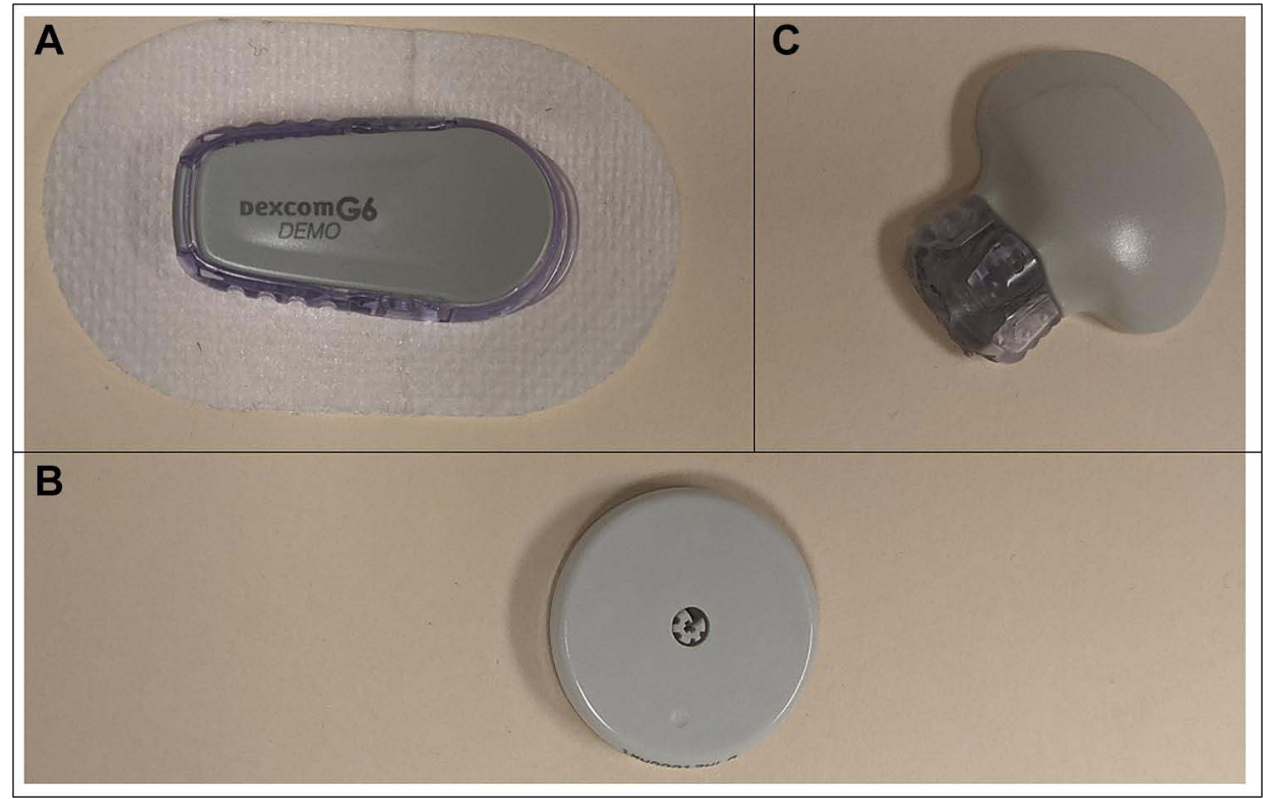

Figure 2 Commercially available subcutaneous CGM devices: (A) Dexcom G6 sensor and transmitter, (B) Abbott Freestyle Libre, (C) Medtronic Guardian sensor 3 sensor and transmitter.

keep blood glucose levels in target range (Figure 3). AID systems have been found to improve glycemic control compared to conventional insulin pump therapies and to reduce the risk of hypoglycemia. ${ }^{19,20}$
Despite the benefits associated with the use of diabetes technology, ongoing barriers to technology adoption are well recognized and include common themes: (i) physical burden concerns, including continual attachment to a device and

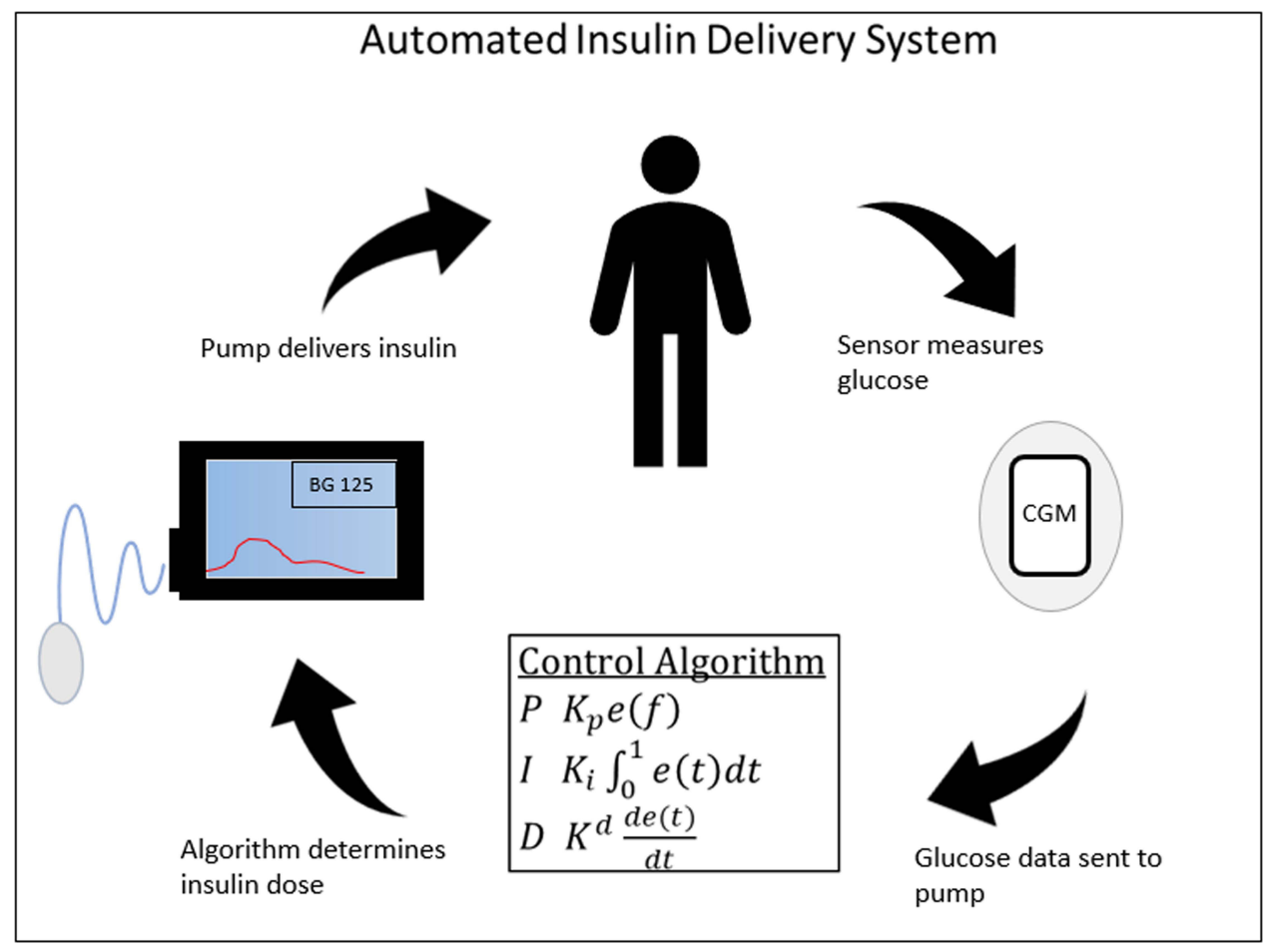

Figure 3 Automated Insulin Delivery System Diagram depicting closed-loop control. The CGM measures the person's glucose value and then feeds the glucose measurement into the control algorithm. The algorithm determines the real-time dose of insulin need by the person. The pump is then commanded to provide that insulin dose, which alters the glucose value. The cycle then repeats. 
hindrance in physical activity, cosmetic impact, and skin injury; (ii) patient and family attitudes to and expectations of technology; (iii) lack of resources for healthcare providers and provider negative attitudes towards technology; (iv) lack of access related to incomplete coverage and high cost; (v) racial and ethnic disparities in device use possibly related to provider and/or patient biases about device use; and (vi) psychosocial barriers. It is important to understand barriers to uptake of not only the AID systems but also their component devices (insulin pump and CGM) to support all those with T1D in utilizing these devices and optimizing health benefits. The purpose of this article is to summarize the current AID devices available for use in management of T1D, review common barriers to uptake of those systems and their component devices, and provide expert opinion on existing and future solutions to identified barriers.

\section{Overview of Automated Insulin Delivery Systems}

Insulin pump and CGM technologies have been increasingly combined over the past decade, moving from SAP to predictive low glucose insulin suspension (PLGS) and then to AID systems. ${ }^{21}$ AID systems are the most recent advancement within diabetes technology and are also referred to as hybrid closed-loop (HCL) systems, utilizing both insulin pumps and CGMs with software algorithms to allow automatic modulation of insulin delivery rate based on sensor-derived glucose levels to minimize both hyperand hypoglycemia (Figure 4). There are multiple HCL systems approved by the United States Food and Drug Administration (FDA) and/or European Medical Agency (EMA), with many more under pre-clinical and clinical development. In this article, we will highlight selected systems that are expected to be used in clinical diabetes care at the time of publication. This will not be a complete list of systems that are under development.

Most commercial AID systems utilize pumps that deliver insulin through tubing that connects the pump to an infusion cannula on the skin. The Medtronic MiniMed $670 \mathrm{G}$ was the first commercially available AID system (Figure 4A), FDA approved in 2016, and consists of the Medtronic $670 \mathrm{G}$ insulin pump paired with the Guardian 3 sensor. It can be used as a sensor-augmented insulin pump (Manual Mode) with the option of using a predicted low glucose suspend feature, which suspends insulin delivery 30 minutes before hypoglycemia is predicted to occur, or as an automated insulin delivery system (Auto Mode) with an embedded algorithm to allow automated basal insulin delivery based on the total daily insulin dose from the

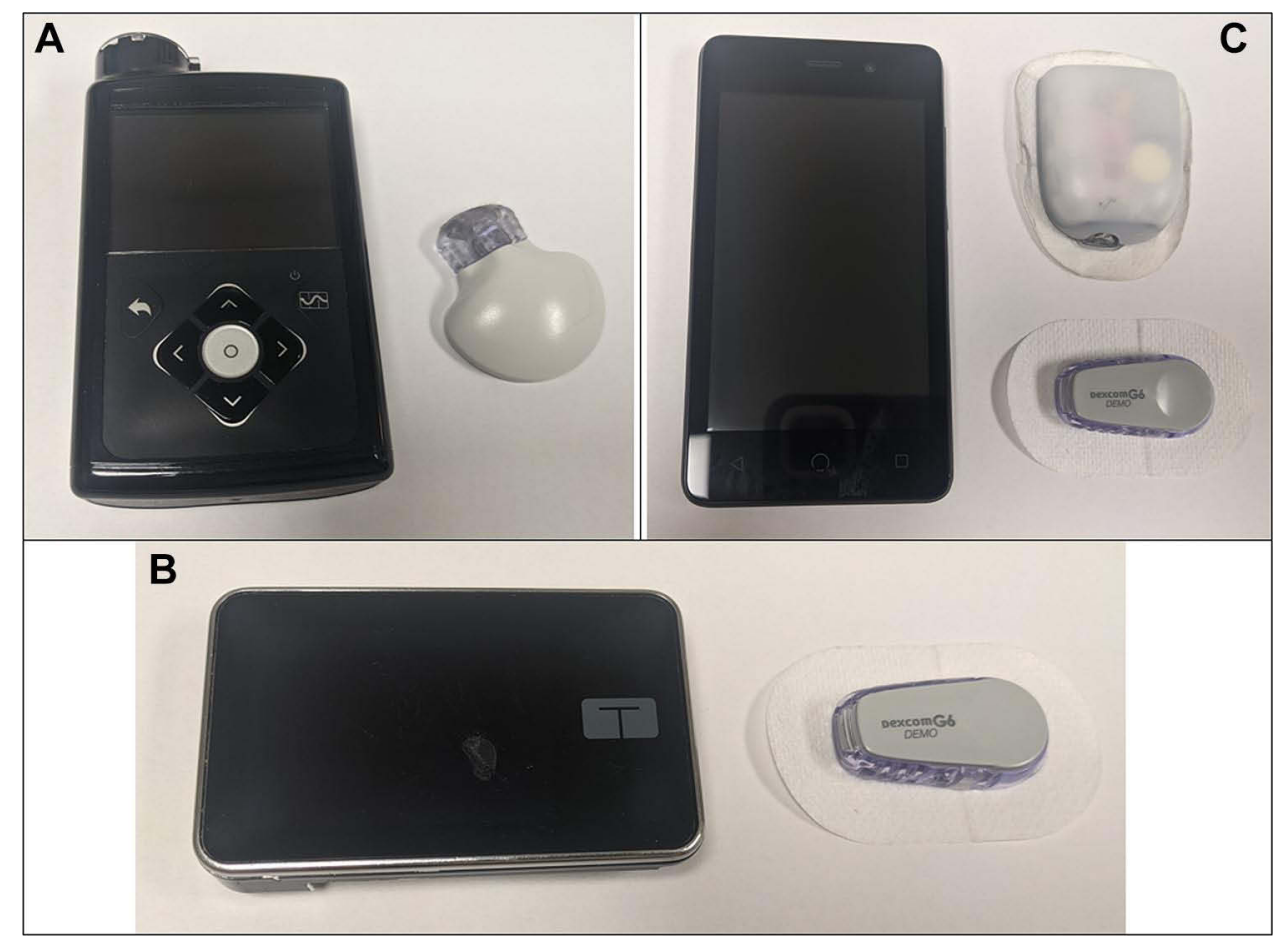

Figure 4 Selected Automated Insulin Delivery Systems: (A) Medtronic 670G insulin pump with Guardian sensor 3 CGM, (B) Tandem t:slim X2 insulin pump with ControlIQ algorithm with Dexcom G6 CGM, (C) Omnipod patch pump with PDM and Dexcom G6 CGM. 
previous 6 days and the current sensor-derived glucose value, with a set target glucose of $120 \mathrm{mg} / \mathrm{dL} .^{22,23}$ Studies have shown increased TIR, decreased time in hyperglycemia and hypoglycemia, and reduced $\mathrm{HbAlc}$ with use of the 670 G AID system in pediatric and adult patients. ${ }^{24-29}$ The next generation of Medtronic AID system, MiniMed $780 \mathrm{G}$, is approved by the EMA and is under review by the FDA at the time of writing. The $780 \mathrm{G}$ can pair with either the same Guardian 3 sensor or a more advanced factorycalibrated Guardian 4 sensor and includes automated insulin delivery with a more robust hyperglycemia reduction algorithm, fewer automated system exits, and with the option for target glucose value to be set at 100,110 , or $120 \mathrm{mg} / \mathrm{dL}$. The advanced hyperglycemia reduction algorithm administers auto-correction boluses to a fixed glucose target of $120 \mathrm{mg} / \mathrm{dL}^{30}$ Studies have demonstrated improvement in TIR, improved time in Auto Mode, and improved user experience without increased time in hypoglycemia with use of this system. ${ }^{30-34}$

Tandem t:slim X2 with Control-IQ technology is another AID device, and was FDA approved in 2019 (Figure 4B). This system utilizes the Dexcom G6 CGM to predict glucose levels 30 minutes into the future and adjust basal insulin doses accordingly, as well as administering automatic correction doses if glucose levels rise above target range. ${ }^{35-37}$ Studies have demonstrated significant improvement in TIR and reductions in hypoglycemia for children and adults using this device, ${ }^{35,38-40}$ as well as improvement in psychosocial outcomes. ${ }^{35,36}$

The Omnipod 5 System is the first tubeless AID system (Figure 4C). It consists of an on-body adhesive patch insulin pump (Pod) paired with the Dexcom G6 CGM and an embedded novel software algorithm to allow automated insulin delivery based upon customizable glucose targets (adjustable by time of day) and sensor-derived glucose values (current and predicted future values). The Omnipod 5 system will provide the option of pod control via a wireless, handheld device, referred to as a PDM, or via a downloadable mobile app on the user's personal smartphone. $^{23,41}$ At the time of writing, this system is under review by the FDA. In children and adults with T1D, studies have shown increased TIR, decreased HbA1c, decreased time in hypoglycemia, and decreased number of hypoglycemic events per person per day when utilizing this system for diabetes management. ${ }^{41-43}$

Several cellphone-based HCL systems are marketed in Europe with CE Mark certification. The Diabeloop system uses a phone-based algorithm communicating with the
Kaleido patch pump and a Dexcom G6 CGM. Several small out-patient studies have been published in adults using this system. ${ }^{44,45}$ A pilot trial of 8 adults using the system for 3 weeks demonstrated a TIR of $70.2 \%$ with $2.9 \%$ time $<70 \mathrm{mg} / \mathrm{dL}^{4}{ }^{44}$ A 6 -month follow-up study of 25 adults demonstrated a TIR of $69.7 \%$ with $1.3 \%$ time $<70 \mathrm{mg} / \mathrm{dL}^{45}$ The CamAPS FX HCL system uses a cell phone-based algorithm communicating with the Dana insulin pump and a Dexcom G6 CGM. ${ }^{46}$ Studies on this algorithm have demonstrated TIR values in the $70-72 \%$ range in various age groups and with different insulin concentrations. ${ }^{47-49}$

\section{Barriers to Device Uptake \\ Barriers Related to Physical Issues}

Whether utilizing an individual insulin pump, CGM, or both within an AID system, these devices should be worn continuously to optimize health and lifestyle outcomes. Physical interference from wearing a device is a commonly endorsed barrier to uptake and continuation of both CGM and insulin pumps. One study determined this to be the biggest barrier to initiation of insulin pump therapy by parents for their children with T1D, outweighing effectiveness or cost of the technology. ${ }^{50}$ Specific aspects of "physical interference" may include physical discomfort, interference with activity, and concern for skin reactions. ${ }^{50}$ Concern regarding physical burden from continuous attachment to a device and concern about the size of the devices have been echoed in other pediatric and adult studies ${ }^{51-55}$ and are cited as reasons for discontinuation of $\mathrm{CGM}^{54,56}$ and insulin pump use. ${ }^{57-59}$ In young children with smaller bodies and increased physical activity, these issues may be even more significant due to limited on-body "real estate" for device site rotation. ${ }^{17,21}$ Nevertheless, from 2016 to 2018, the largest uptake of insulin pump and CGM therapies was in children. ${ }^{1}$

These devices are often visible to others, prompting cosmetic insecurities in the wearer such as feeling less attractive or feeling different from others. ${ }^{16,54,60,61}$ Concern about how the device looks on the body is a concern for all users, but is more frequently reported by females compared to males. ${ }^{54} \mathrm{In}$ older children, an increased sense of disease and embarrassment around peers were cited as reasons for discontinuation of CSII therapy. ${ }^{54,58,59}$ Pump and CGM users have reported feeling "shackled" to their devices, like they look like a "cyborg". 16,51,60 These body image concerns have inspired an industry around clothing and accessories meant to support 
and/or conceal medical devices. Some available products include discreet or fashionable belts or body wraps to hold insulin pumps and accommodate tubing, as well as many different clothing brands for men and women with ergonomically-placed pockets that can support and conceal insulin pumps. There are adhesive products for use with CGMs and patch pumps that are made with attractive designs, as well as pump cases and covers with designs that mimic those used with cell phones.

Dermatologic complications may occur with use of CGM or insulin pumps, as both include a cannula or filament inserted under the skin and secured with adhesive. CGMs are left in place for 7 to 14 days, depending on the device, and insulin pumps are typically exchanged every 2 to 3 days. Skin issues are a significant concern for patients utilizing these technologies, as well as those considering implementing these devices, ${ }^{16,17,62,63}$ and have also been cited as a reason for discontinuation of CGM use. ${ }^{56}$ Some examples of reported skin complications include scarring, erythema, lipohypertrophy, lipoatrophy, nodules, abrasions, hyperpigmentation, itching, wounds, eczema, and bruising. ${ }^{62,64,65}$

A recent study by Berg et $\mathrm{al}^{62}$ described the prevalence of and risk factors associated with dermal complications among pediatric and adolescent T1D patients using CSII and/or CGM. Skin complications were reported by $89.5 \%$ of those patients using CSII and $79.5 \%$ of those currently using or who had previously used CGM. The most frequent complaints were itching, eczema, and wounds for both CSII and CGM use. At the time of the study, $62.9 \%$ of CSII users and $46 \%$ of current CGM users had at least one site with a currently visible dermatological condition. This study noted an association between dermal complications and a personal history of atopy, which has been noted previously. ${ }^{66}$

Additional physical barriers may play a role in device use among people with diabetes, though many have not been thoroughly studied. Older adults with longstanding diabetes have been demonstrated to have worsened scores on manual dexterity testing. ${ }^{67}$ While reduced dexterity has been discussed as a barrier to broad-spectrum device use, it appears to have been mostly studied regarding use of insulin pens. ${ }^{68}$ Loss of vision related to diabetic retinopathy is a major source of morbidity among people with longstanding diabetes. Despite this, there appears to be little literature regarding device use among people with limited visual acuity, with existing research focused also on insulin pen use. ${ }^{69}$ Cognitive impairment, particularly among elderly adults, has also been cited as a potential barrier to device use. The WISDM study investigated CGM use among adults 60+ years old and found that CGM use was associated with a significant reduction in hypoglycemia, but no change in cognition-related outcomes. $^{70}$

\section{Barriers Related to Technology Expectations and Utilization}

Incorporating devices into diabetes management requires further education from medical providers and more intensive follow-up, and may require more action from users to optimize device use. ${ }^{71}$ With AID systems, users need to be competent in troubleshooting issues, such as interruptions with connectivity, software malfunctions or updates, and infusion tubing/catheter malfunctions. They should feel comfortable entering/exiting the automated insulin delivery mode, navigating all device settings, and making adjustments as needed. ${ }^{72}$ This causes concern for some that the technology may be too complicated for them to confidently utilize and is often noted as a barrier to uptake of these devices. ${ }^{50,51}$ Parents of children with T1D sometimes describe concern regarding malfunction and risk of hypoglycemia associated with pump use, despite research suggesting pump use is associated with reduction in hypoglycemia. ${ }^{50}$ This further highlights the importance of device users feeling comfortable navigating and responding to the devices.

For example, to maintain automated insulin delivery (Auto Mode) with the MiniMed 670G AID system (the first generation of AID system), users are required to continuously wear the CGM and calibrate at least twice per day, as well as respond to alerts within an appropriate time period. Users are forced out of Auto Mode if prolonged hyperglycemia occurs (glucose $>250 \mathrm{mg} / \mathrm{dL}$ for 3 hours or $>300 \mathrm{mg} / \mathrm{dL}$ for 1 hour), the pump has delivered minimum insulin delivery rate for $2.5 \mathrm{hr}$ or maximum insulin delivery rate for 4 hours, or sensor glucose data are missing or inaccurate. ${ }^{73}$ Not surprisingly, one study showed high rates of Auto Mode exit and $\sim 30 \%$ of youth discontinuing AID altogether within the first 6 months of use, citing difficulty maintaining Auto Mode and excessive alarms as some reasons for discontinuation. ${ }^{73}$ It should be noted that compared to the 670G AID system, newer systems have improved features that reduce the burden of use, such as no defined minimum/maximum delivery 
exits and incorporating CGMs that do not require calibration.

The addition of diabetes technology may increase the overall burden of management in some, rather than mitigating it, as seen with use of the $670 \mathrm{G}$ AID system. This is another frequently named barrier to uptake of diabetes technology, ${ }^{74}$ and may be attributed to device abilities falling short of users' expectations. Another study using the previously detailed MiniMed 670G AID system noted that users with little previous knowledge about the system found the devices required more input and burdensome tasks than expected. Participants felt "closed loop" and "artificial pancreas" terminology implied that the system would require no input from the user. ${ }^{75}$ This theme was supported in a 2018 review article investigating uptake of CSII alone, which reported differences between initial expectation and lived experience with insulin pump use, although many users reported feeling that the device provided more flexibility and improved the burden of diabetes self-management at the end of the study. ${ }^{76}$

Although having diabetes-related data readily available may seem beneficial to technology users, the concern for potential "information overload" is a cited source of hesitation. This is especially true regarding CGM use, as CGM provides continuous real-time blood glucose data and alerts for alarming glucose values or trends. ${ }^{52,77}$ Indeed, some studies suggest users may actually experience increased levels of diabetes-related stress when utilizing devices, secondary to continuous availability of data, and frequent alarms. ${ }^{16,17,52,54,61,73,78}$

\section{Barriers Related to the Healthcare Team}

Diabetes health care providers serve an important role in promoting uptake of and adherence to devices. These clinicians are often the main source of information regarding diabetes treatment options, and are PwD's primary resource for education, support, and troubleshooting for devices, which is necessary when initiating and continuing use of technology. ${ }^{52,57,76,79,80}$ With such a substantial role, diabetes care facilities must have appropriate availability of staff who are educated and experienced with the devices to provide the necessary education and support for those utilizing diabetes technology. ${ }^{81}$ This can be challenging for healthcare teams, as demonstrated in a 2012 UK-wide insulin pump audit, which concluded that the main barrier to access of insulin pump therapy for people with T1D was lack of funded healthcare professional time required to deliver CSII services and patient support. ${ }^{82}$ In addition, clinicians should feel comfortable prescribing devices and supporting patients with their use, as healthcare provider attitudes surrounding diabetes technology have been shown to impact the likelihood of uptake of these devices. ${ }^{78}$ Specifically, it has been suggested that clinicians with positive attitudes to diabetes technology are more likely to have more patients on insulin pumps and CGMs than do clinicians with negative attitudes to technology. ${ }^{52}$

Concerns regarding "gatekeeping" by healthcare providers have been discussed in multiple studies, ${ }^{71,83}$ whereby providers may limit recommending diabetes technologies to PwD who they perceive to be likely to appropriately utilize the devices. ${ }^{83}$ This may be partially influenced by historical treatment guidelines which recommend considering insulin pump therapy for patients who check their glucose level at least 4 times per day, administer at least 4 insulin injections per day, seek to optimize glycemic control, and are willing to utilize complex insulin therapy with continued interaction with their diabetes care provider. $^{84,85}$ One study looking at insulin pump use in pediatric patients demonstrated that pump use was associated with more frequent blood glucose checks and with CGM use. This may indicate that more engagement with diabetes management may tend toward increased utilization of technologies or may also reflect that engagement with self-management may influence healthcare providers to recommend diabetes technology use. ${ }^{50}$ Another example includes a small study of people with T1D in Ireland. Participants reported significant frustration with provider "gatekeeping" and fewer than half of participants reported ever receiving information about CSII from their diabetes provider. ${ }^{71}$

It is impossible to perfectly predict which individuals with diabetes will be successful in utilization of diabetes technology, and clinicians' perception of patient readiness should not be the sole factor in determining device use. In fact, patients and clinicians often have differing perceptions of patients' device readiness. One study showed that diabetes educators perceived patients to have a lack of understanding regarding what to do with information received from diabetes devices and a lack of understanding of the features of those devices, which they felt to be a significant barrier to pump and/or CGM use. Adults with T1D did not endorse that barrier for themselves nearly as often, with $\sim 45 \%$ of clinicians perceiving this barrier to be true for their patients, while only $4.5 \%$ of adults with T1D endorsed that for themselves. ${ }^{52}$ 
An additional barrier faced by the healthcare team is access to and support for telehealth and telehealth monitoring. All commercial insulin pump and CGM systems support digital uploads of data, many via perpetually connected devices requiring no user interaction to upload. The COVID-19 pandemic has seen an explosion in the demand for telehealth for diabetes as well as publications on this subject. ${ }^{86,87}$ Despite the growth in this area, many device users still struggle with device uploads and many practices struggle with obtaining digital downloads from their patients. Additionally, reimbursement for remote review of CGM and pump data and telemedicine across state lines remain major barriers to growth of this form of care in the United States. Telehealth device training and tuning has also grown during the COVID-19 pandemic, which has required retraining and reorganization of healthcare teams, creating additional administrative burdens for many centers.

\section{Barriers Related to Cost}

Insulin delivery device uptake is noted to be lower in people of lower socioeconomic status (SES) ${ }^{88}$ and cost is a frequently reported barrier to utilization of diabetes technology devices, ${ }^{52-54,71,81}$ including insulin pumps $^{50}$ and other AID systems. ${ }^{85,89}$ Cost is also a common reason for CGM discontinuation in adults with T1D. ${ }^{54}$ One qualitative study evaluated cost considerations of diabetes technology in children and adults with T1D and included parents and partners of those participants. ${ }^{89}$ The impact of cost was assessed at 5 different levels: policy, organizational, insurance, interpersonal, and individual. Participants expressed concern about financial accessibility for all, noting that diabetes technology seems to be utilized first by those of higher SES. Participants reported that insurance coverage feels necessary to afford diabetes medical management and often dictates what is included in diabetes management, which may not align with patient preference, provider recommendation, or recent research study findings. Coverage may be insufficient with public insurance, thus raising barriers to optimal T1D therapies, such as requiring an overwhelming amount of "evidence" before reimbursing for technology. Most participants discussed weighing cost against benefit of devices, and some anticipated the cost to be too great to consider uptake of the devices, while others felt the benefits outweighed the costs, with one participant stating, "I would sell my house ... I would do whatever I had to do." Participants also reviewed burden from non-monetary costs, such as time spent on phone calls and outreach to insurance companies, pharmacies, and doctors' offices to secure diabetes services. ${ }^{89}$

Inadequate support from national government and insurance is a recognized barrier to uptake of diabetes devices, ${ }^{50,52}$ and despite studies demonstrating costeffectiveness of AID systems, ${ }^{90,91}$ reimbursement continues to vary internationally and across payers in the United States, likely contributing to the variation in diabetes technology uptake trends. For example, CSII device uptake in the US is noted to be around $\sim 60 \%$ for both children and adults with T1D, ${ }^{1}$ but only $34.7 \%$ for children and $6.8 \%$ for adults in Ireland. ${ }^{92}$ According to the Euro Diabetes Index 2014, many European countries were found to have CSII uptake at over $15 \% .{ }^{93}$ Australia was noted to have $\sim 10 \%$ of the T1D population using CSII technology, with half of those users being under age $25 .{ }^{81}$ In Australia, absence of government financial support for CSII after age 18 is reported to significantly hinder uptake or continued use of these devices. In addition, lack of formal organizational policy or guidelines on diabetes care is felt to be a significant barrier to technology use in T1D. ${ }^{81}$ A qualitative study from Ireland showed similar results, with adults with T1D reporting concern regarding lack of standardization of diabetes care. Authors concluded that, if national policy provided direction and structure for healthcare providers regarding T1D care, this may improve medical providers' awareness of diabetes technology and thus improve CSII uptake. $^{71}$

Argento's study on the impact of United States' Medicare coverage policies related to CSII devices revealed that many users report dissatisfaction with coverage and feel the policies in place surrounding diabetes management supplies are restrictive. Participants also discussed difficulty with receiving insulin pump supplies in a timely manner, which encourages behaviors that deviate from device recommendations, such as leaving insulin infusion sites in the skin longer than recommended, reusing single-use supplies, or discontinuing use of the device altogether. These behaviors often led to adverse outcomes, including hyperglycemia, hypoglycemia, overall glucose variability, increased anxiety/frustration, and pain, irritation, and/or scarring at infusion sites. ${ }^{94}$ Regardless of government or private insurance coverage, inadequate financial support is a consistently reported barrier, as some people with T1D in the US describe private 
insurance plans to have out of pocket costs that are ultimately prohibitive against device use. ${ }^{95}$

\section{Barriers Related to Disparities}

Racial and socioeconomic (SES) disparities in access to diabetes technology are an ongoing concern, ${ }^{96}$ demonstrated across all age groups in many different countries, with data from the US T1D Exchange, ${ }^{1}$ the German/ Austrian Prospective Diabetes Follow-up Registry, and the English/Welsh National Paediatric Diabetes Audit all noting racial and SES disparities. ${ }^{10}$ Data shows that nonHispanic whites and female youths are more likely to utilize insulin pumps than other groups. Other characteristics associated with diabetes technology utilization in youth include having private health insurance, being from higher income families, living in a two-parent household, and having parents with higher education..$^{50,56,85,97,98}$ Although utilization of technology is noted to be increasing, especially in the pediatric population, this increase has been noted preferentially in youth from higher SES groups, with the gap in technology use between low SES and higher SES continuing to widen. ${ }^{88,99}$ Similar findings are seen in the adult T1D population, with private insurance, higher education, and higher household income associated with increased technology utilization. Lower rates of insulin pump use are seen in males, racial and ethnic minorities, and those with no insurance or government insurance. $^{11,56,98,100}$ Additional concern comes from the possibility that these disparities in access may translate into differences in health outcomes, with some studies suggesting an association between SES and $\mathrm{HbAlc}$ in youth. ${ }^{88}$

A 2015 study on disparities demonstrated that even in the highest income levels $(\geq \$ 100,000$ per year), nonHispanic white youth were significantly more likely to use an insulin pump than non-Hispanic black youth at the same income level ( $73 \%$ vs $45 \%$, respectively; p $<0.001$ ). ${ }^{101}$ Then in 2018, a study by O'Connor investigated if disparities in insulin pump use persisted following increasing rates of pump utilization in the years prior. This study identified an association that had not been previously described: patients/families with non-English preferred languages had lower insulin pump use rates. ${ }^{100}$

Racial and SES disparities are complex and likely multifactorial in nature. Provider implicit bias may impact all aspects of patient care, including patient-provider interactions, treatment decisions, treatment adherence, and even patient health outcomes, ${ }^{102}$ and the fact that these disparities are consistent across multiple countries with differing levels of government policy and financial support may be suggestive of influence from medical provider bias. For example, the likelihood of a provider recommending diabetes technology has been suggested to be influenced by insurance status, with this bias becoming more prevalent as practice years increased (but not age). ${ }^{103}$ Commissariat's study considers if the disparity is not solely from medical provider bias, but also that PwD from lower SES backgrounds face greater financial constraints and therefore may limit utilization of technologies, given the significant burden of cost with these devices. Those with high SES backgrounds may have more disposable income for diabetes supplies and to enroll in private insurance. This study does then question if the presence of fewer financial constraints may influence healthcare providers to recommend technology use. ${ }^{50}$ Additionally, as discussed previously, there are significant non-monetary costs to diabetes technology use related to time spent at medical visits and on phone calls related to education and support surrounding device use, as well as outreach and troubleshooting to obtain and maintain device supplies. This implies that those who utilize these technologies must not only have a degree of disposable income but also a degree of disposable time.

\section{Psychosocial Barriers}

Assessment of psychosocial outcomes related to diabetes technology is a relatively new concept, and therefore less is known regarding psychosocial concerns as a barrier to diabetes technology utilization and the impact of these devices on psychosocial outcomes. Existing studies report varying results. Generally, implementation of diabetes technology provides positive health benefits without worsening psychosocial outcomes and perceived burden of diabetes management, ${ }^{36}$ with some studies demonstrating improvement in psychosocial outcomes. Specifically, studies regarding the impact of diabetes devices on quality of life have shown mixed results, although many demonstrate improved or higher quality of life in those utilizing technology and/or their caregivers compared to those not utilizing technology. ${ }^{16,104-109}$

Depression and anxiety are two additional factors with mixed study results. In those utilizing AID systems, some users reported increased anxiety and depressive symptoms, ${ }^{110}$ with other studies reporting either no impact on symptoms based on insulin delivery method or a reduction in symptoms when utilizing CSII compared 
with MDI. ${ }^{108,109}$ Another study demonstrated an association between higher depressive scores and PwD transitioning from CSII to MDI, but transitioning from MDI to CSII subsequently resulted in a decrease in symptoms. This suggests that increased depressive symptoms may influence PwD to transition their insulin delivery method, regardless of method utilized. ${ }^{111}$ Similarly, increased levels of anxiety have been associated with discontinuation of CSII. ${ }^{58,112}$ Additionally, despite the evidence that diabetes technology is associated with reduced hypoglycemia, fear of device malfunction resulting in hypoglycemia is a concern reported by PwD and parents of children with T1D. Studies investigating the impact of technology on fear and anxiety surrounding hypoglycemia have reported mixed results, with some demonstrating no impact and others suggesting positive impacts. ${ }^{16,113-116}$ Use of diabetes technology has shown to positively impact sleep for parents of children with T1D, possibly related to decreased fear of hypoglycemia. ${ }^{17,36}$

\section{Expert Opinion on Potential Solutions}

Diabetes technologies have progressed significantly in the past two decades, from rarely used and novel adjunctive agents to the essential elements of physiologic glycemic control for many people with diabetes. The growth in use of these technologies has generally been associated with reductions in device burden, improvements in device features, improvements in payer coverage, and increased device knowledge and education among PwD and providers. Increased device use has been gradual overall, though with some notable rapid increases after availability of novel features such as factory calibrated CGMs or AID systems. Through this, we see that device use is influenced by the perceived benefit to burden ratio. Improved benefits often synergize with reduced burdens, such that multiple burdens may be reduced by a single improvement. For example, improved sensor accuracy removed the burden of CGM calibrations, which improved percent device wear thus further improving glycemic control. Demonstration of the correlation between CGM use and improved glycemic control then improved CGM coverage by payers, further improving sensor wear. Despite these advances, there remain several conditions and situations for which insufficient evidence exists to recommend HCL technologies. Diabetes in pregnancy, whether type 1 , type 2 , or gestational, is still being studied regarding HCL systems. ${ }^{117}$
Use of HCL technology during hospital admissions is also currently under study, and not yet clinically indicated.

\section{Potential Solutions to Physical Barriers}

Barriers related to the physical body are often those first mentioned during device discussions. Commonly, active people and parents of young children are concerned about the hindrance of pump tubing. For these people, a patchpump such as the Insulet Omnipod Eros, Dash, or emerging OP5 may present an ideal solution. Other companies are currently developing additional non-disposable patchpumps, which may use a short length of tubing to a proximal detachable infusion set. The size and discomfort of early CGMs was a major barrier to their adoption. CGM devices are continuing to get smaller with subsequent iterations. The Dexcom G7 and Abbott Freestyle Libre 3 are each at least $33 \%$ smaller than their predecessors, with fully disposable designs. Such improvements in device form-factor should make these technologies more acceptable to a wider range of users. Emerging devices are also expected to last for 14 or more days, reducing the overall pain of device placement. While some users may report difficulties using devices due to their work or recreational environments, these concerns are not well supported by real-world use. There are numerous high school, college, and professional athletes who utilize CGM and insulin pump technologies during extreme conditions. Our own group has studied HCL technology during winter sports and demonstrated the safety of these systems during extremes of temperature, altitude, and exercise, even among young children. ${ }^{118,119}$

Dermatological issues are a noted barrier to device use. Our group has developed free online resources to help educate providers and device users on skin care solutions (https://www.bdcpantherdiabetes.org/tools/skin-solutionstips). Many common skin issues can be improved or prevented by proper site selection and rotation, use of barrier wipes or tapes, application of topical steroids, proper removal aids and techniques, and post-wear skin care. In addition, device manufacturers are constantly working to reduce the irritation and skin reactions of new and emerging devices.

The limited survival of insulin pump infusion sets is another major device burden for many users. Preliminary research by ConvaTec, Medtronic, and Capillary Biomedical, among others, is showing the potential for infusion sets to function for 7-10 days. ${ }^{120}$ The ConvaTec study published by Lal demonstrated a median wear time 
of 9.1 days. Such progress has the potential to limit set changes to a once-a-week occurrence, further reducing the burden of pump and AID system use. Another potential benefit of prolonged infusion site wear is the ability to combine a 7-day infusion site and 7-day sensor into a single on-body device. The combined infusion set and sensor would greatly reduce on-body device burden.

Another associated physical burden is the visibility of diabetes when interacting with an apparent medical device (insulin pump) in public, to bolus insulin at mealtimes. This is a frequently cited concern among many adolescents and young adults. The ability to bolus from a smartphone would greatly reduce this burden and serve as another benefit of device utilization compared to MDI. The CamAPS system in the United Kingdom is the world's first HCL design to offer phone-based control, with noted burden reduction among device users. ${ }^{121}$ The Insulet OP5 system has been announced to offer phone-based control once available within the United States. ${ }^{42}$

\section{Potential Solutions to Cost Barriers}

While device costs remain a major issue for many PWD and their families, overall device coverage is improving, and cost-benefit analysis of diabetes technologies is generally favorable. A recent pair of publications examined the Centers for Medicare and Medicaid Services coverage criteria for insulin pumps and CGMs. ${ }^{122,123}$ These commentaries call for coverage criteria based on modern device use profiles and evidence-based requirements. They also note the demonstrated cost effectiveness of CGM and CSII technologies. Furthermore, they discuss the burdens placed on providers to satisfy arbitrary documentation requirements. Adoption of these recommended coverage criteria would reduce provider burden and move diabetes technology coverage to the level supported by current evidence.

\section{Potential Solutions to Disparity-Based}

\section{Barriers}

Disparities in diabetes technology use among racial and ethnic minorities is an emerging area of concern for many in the technology field. A noted driver of these disparities is underrepresentation among black and Hispanic populations in many areas of technology research. This problem is now receiving attention from the National Institutes of Health, Food and Drug Administration, and many industry partners who together are calling for increased recruitment among these populations in future development and approval studies. Additionally, authors within disparity literature are calling for objective criteria to be used for CGM and insulin pump prescribing to combat possible implicit bias among providers. Such an effort may synergize with efforts to remove unnecessary device coverage requirements.

\section{Conclusion}

In conclusion, use of insulin pumps, continuous glucose monitors, and automated insulin delivery systems improves glycemic control and glycemic outcomes among people with diabetes. Advances in these technologies have increased their overall use. Despite these advances, there remain barriers to broader device adoption, including those related to physical burdens, device expectations, provider education, costs, racial/ethnic disparities, and psychosocial concerns. While it is impossible to remove all barriers, work is underway to reduce these burdens on numerous fronts, including research, development, and advocacy. With continued research, we expect to see reduced device burdens, improved device benefits, and overall improved care for people with diabetes.

\section{Abbreviations}

T1D, type 1 diabetes; HbA1c, hemoglobin A1c; TIR, time in range; LAI, long-acting insulin; RAI, rapid-acting insulin; MDI, multiple daily injection; CSII, continuous subcutaneous insulin infusion; CGM, continuous glucose monitor; $\mathrm{PwD}$, person with diabetes; SAP, sensor-augmented pump; AID, automated insulin delivery; PLGS, predictive low glucose insulin suspension; HCL, hybrid closed-loop; FDA, United States Food and Drug Administration; EMA, European Medical Agency; SES, socioeconomic status.

\section{Acknowledgment}

MEP is supported by NIH/NIDDK Grant/Award Number 5T32DK063687-18.

\section{Disclosure}

MEP reports no conflicts of interest. $\mathrm{CB}$ is a consultant for and reports honoraria from Insulet Corp, during the conduct of the study. LHM has received speaking/consulting honoraria/personal fees from DexCom, Inc., speaking/consulting honoraria/personal fees and grants from Tandem Diabetes, and grants from Beta Bionics and NIH, outside the submitted work, and consults for Capillary Biomedical and Beta Bionics. Her institution receives research/project grants from Medtronic, Tandem Diabetes, Beta Bionics, Dexcom, Abbott, and Insulet Corp. GPF conducts research 
sponsored by Medtronic, Dexcom, Abbott, Tandem, Insulet, Beta Bionics, and Lilly and is a consultant/ speaker/advisory board member for Medtronic, Dexcom, Abbott, Tandem, Insulet, Beta Bionics, and Lilly, and reports grants and personal fees from Medtronic, Dexcom, Abbott, Insulet, Tandem, Beta Bionics, and Lilly, during the conduct of the study. The authors report no other potential conflicts of interest for this work.

\section{References}

1. Foster NC, Beck RW, Miller KM, et al. State of type 1 diabetes management and outcomes from the T1D exchange in 20162018. Diabetes Technol Ther. 2019;21(2):66-72. doi:10.1089/ dia.2018.0384

2. American Diabetes Association. Classification and diagnosis of diabetes: standards of medical care in diabetes-2021. Diabetes Care. 2021;44(Suppl 1):S15-S33. doi:10.2337/dc21-S002

3. Hamman RF, Bell RA, Dabelea D, et al. The SEARCH for diabetes in youth study: rationale, findings, and future directions. Diabetes Care. 2014;37(12):3336-3344. doi:10.2337/ dc14-0574

4. Mayer-Davis EJ, Lawrence JM, Dabelea D, et al. Incidence trends of type 1 and type 2 diabetes among youths, 2002-2012. N Engl $J$ Med. 2017;376(15):1419-1429. doi:10.1056/NEJMoa1610187

5. American Diabetes Association. Children and adolescents: standards of medical care in diabetes-2021. Diabetes Care. 2021;44 (Suppl 1):S180-S199. doi:10.2337/dc21-S013

6. Battelino T, Danne T, Bergenstal RM, et al. Clinical targets for continuous glucose monitoring data interpretation: recommendations from the international consensus on time in range. Diabetes Care. 2019;42(8):1593-1603. doi:10.2337/dci19-0028

7. Perez-Nieves M, Juneja R, Fan L, Meadows E, Lage MJ, Eby EL. Trends in U.S. insulin use and glucose monitoring for people with diabetes: 2009-2018. J Diabetes Sci Technol. 2021;1932296 8211028268. doi:10.1177/19322968211028268

8. Miller KM, Foster NC, Beck RW, et al. Current state of type 1 diabetes treatment in the U.S.: updated data from the T1D exchange clinic registry. Diabetes Care. 2015;38(6):971-978. doi: $10.2337 / \mathrm{dc} 15-0078$

9. Bruttomesso D, Costa S, Baritussio A. Continuous subcutaneous insulin infusion (CSII) 30 years later: still the best option for insulin therapy. Diabetes Metab Res Rev. 2009;25(2):99-111. doi:10.1002/dmrr.931

10. Sherr JL, Hermann JM, Campbell F, et al. Use of insulin pump therapy in children and adolescents with type 1 diabetes and its impact on metabolic control: comparison of results from three large, transatlantic paediatric registries. Diabetologia. 2016;59 (1):87-91. doi:10.1007/s00125-015-3790-6

11. Pihoker C, Badaru A, Anderson A, et al. Insulin regimens and clinical outcomes in a type 1 diabetes cohort: the SEARCH for Diabetes in Youth study. Diabetes Care. 2013;36(1):27-33. doi:10.2337/dc12-0720

12. Laffel LM, Kanapka LG, Beck RW, et al. Effect of continuous glucose monitoring on glycemic control in adolescents and young adults with type 1 diabetes: a randomized clinical trial. JAMA. 2020;323(23):2388-2396. doi:10.1001/jama.2020.6940

13. Riddlesworth T, Price D, Cohen N, Beck RW. Hypoglycemic event frequency and the effect of continuous glucose monitoring in adults with type 1 diabetes using multiple daily insulin injections. Diabetes Ther. 2017;8(4):947-951. doi:10.1007/ s13300-017-0281-4
14. Beck RW, Riddlesworth T, Ruedy K, et al. Effect of continuous glucose monitoring on glycemic control in adults with type 1 diabetes using insulin injections: the DIAMOND randomized clinical trial. JAMA. 2017;317(4):371-378. doi:10.1001/jama.20 16.19975

15. DeSalvo DJ, Miller KM, Hermann JM, et al. Continuous glucose monitoring and glycemic control among youth with type 1 diabetes: international comparison from the T1D exchange and DPV initiative. Pediatr Diabetes. 2018;19(7):1271-1275. doi:10.1111/ pedi. 12711

16. Forlenza GP, Messer LH, Berget C, Wadwa RP, Driscoll KA. Biopsychosocial factors associated with satisfaction and sustained use of artificial pancreas technology and its components: a call to the technology field. Curr Diab Rep. 2018;18(11):114. doi:10.1007/s11892-018-1078-1

17. Hilliard ME, Levy W, Anderson BJ, et al. Benefits and barriers of continuous glucose monitoring in young children with type 1 diabetes. Diabetes Technol Ther. 2019;21(9):493-498. doi:10.1089/dia.2019.0142

18. Frontino G, Bonfanti R, Scaramuzza A, et al. Sensor-augmented pump therapy in very young children with type 1 diabetes: an efficacy and feasibility observational study. Diabetes Technol Ther. 2012;14(9):762-764. doi:10.1089/dia.2012.0044

19. Pease A, Lo C, Earnest A, Kiriakova V, Liew D, Zoungas S. Time in range for multiple technologies in type 1 diabetes: a systematic review and network meta-analysis. Diabetes Care. 2020;43 (8):1967-1975. doi:10.2337/dc19-1785

20. Weisman A, Bai JW, Cardinez M, Kramer CK, Perkins BA. Effect of artificial pancreas systems on glycaemic control in patients with type 1 diabetes: a systematic review and meta-analysis of outpatient randomised controlled trials. Lancet Diabetes Endocrinol. 2017;5(7):501-512. doi:10.1016/s22138587(17)30167-5

21. Nevo-Shenker M, Phillip M, Nimri R, Shalitin S. Type 1 diabetes mellitus management in young children: implementation of current technologies. Pediatr Res. 2020;87(4):624-629. doi:10.1038/ s41390-019-0665-4

22. Saunders A, Messer LH, Forlenza GP. MiniMed 670G hybrid closed loop artificial pancreas system for the treatment of type 1 diabetes mellitus: overview of its safety and efficacy. Expert Rev Med Devices. 2019;16(10):845-853. doi:10.1080/17434440.2 019.1670639

23. Cobry EC, Berget C, Messer LH, Forlenza GP. Review of the OmniPod $\left({ }^{\circledR}\right) 5$ automated glucose control system powered by horizon $^{\mathrm{TM}}$ for the treatment of type 1 diabetes. Ther Deliv. 2020;11(8):507-519. doi:10.4155/tde-2020-0055

24. Forlenza GP, Pinhas-Hamiel O, Liljenquist DR, et al. Safety evaluation of the MiniMed 670G system in children 7-13 years of age with type 1 diabetes. Diabetes Technol Ther. 2019;21 (1):11-19. doi:10.1089/dia.2018.0264

25. Lal RA, Basina M, Maahs DM, Hood K, Buckingham B, Wilson DM. One year clinical experience of the first commercial hybrid closed-loop system. Diabetes Care. 2019;42 (12):2190-2196. doi:10.2337/dc19-0855

26. Garg SK, Weinzimer SA, Tamborlane WV, et al. Glucose outcomes with the in-home use of a hybrid closed-loop insulin delivery system in adolescents and adults with type 1 diabetes. Diabetes Technol Ther. 2017;19(3):155-163. doi:10.1089/ dia.2016.0421

27. Bergenstal RM, Garg S, Weinzimer SA, et al. Safety of a hybrid closed-loop insulin delivery system in patients with type 1 diabetes. JAMA. 2016;316(13):1407-1408. doi:10.1001/ jama.2016.11708

28. Da Silva J, Bosi E, Jendle J, et al. Real-world performance of the MiniMed $^{\mathrm{TM}}$ 670G system in Europe. Diabetes Obes Metab. 2021;23(8):1942-1949. doi:10.1111/dom.14424 
29. Duffus SH, Ta'ani ZA, Slaughter JC, Niswender KD, Gregory JM. Increased proportion of time in hybrid closed-loop "Auto Mode" is associated with improved glycaemic control for adolescent and young patients with adult type 1 diabetes using the MiniMed 670G insulin pump. Diabetes Obes Metab. 2020;22 (4):688-693. doi:10.1111/dom.13912

30. Beato-Víbora PI, Gallego-Gamero F, Ambrojo-López A, Gil-Poch E, Martín-Romo I, Arroyo-Díez FJ. Rapid improvement in time in range after the implementation of an advanced hybrid closed-loop system in adolescents and adults with type 1 diabetes. Diabetes Technol Ther. 2021;23(9):609-615. doi:10.1089/dia.2021.0037

31. Carlson AL, Bode BW, Brazg RL, et al. 97-LB: safety and glycemic outcomes of the MiniMed advanced hybrid closed-loop (AHCL) system in subjects with T1D. Diabetes. 2020;69(Supplement1):97-LB. doi:10.2337/db20-97-LB

32. Collyns OJ, Meier RA, Betts ZL, et al. Improved glycemic outcomes with medtronic minimed advanced hybrid closed-loop delivery: results from a randomized crossover trial comparing automated insulin delivery with predictive low glucose suspend in people with type 1 diabetes. Diabetes Care. 2021;44 (4):969-975. doi:10.2337/dc20-2250

33. Bergenstal RM, Nimri R, Beck RW, et al. A comparison of two hybrid closed-loop systems in adolescents and young adults with type 1 diabetes (FLAIR): a multicentre, randomised, crossover trial. Lancet. 2021;397(10270):208-219. doi:10.1016/s01406736(20)32514-9

34. McAuley SA, Lee MH, Paldus B, et al. Six months of hybrid closed-loop versus manual insulin delivery with fingerprick blood glucose monitoring in adults with type 1 diabetes: a randomized, controlled trial. Diabetes Care. 2020;43(12):3024-3033. doi:10.2337/dc20-1447

35. Pinsker JE, Müller L, Constantin A, et al. Real-world patient-reported outcomes and glycemic results with initiation of control-IQ technology. Diabetes Technol Ther. 2021;23 (2):120-127. doi:10.1089/dia.2020.0388

36. Cobry EC, Kanapka LG, Cengiz E, et al. Health-related quality of life and treatment satisfaction in parents and children with type 1 diabetes using closed-loop control. Diabetes Technol Ther. 2021;23(6):401-409. doi:10.1089/dia.2020.0532

37. Brown SA, Kovatchev BP, Raghinaru D, et al. Six-month randomized, multicenter trial of closed-loop control in type 1 diabetes. $N$ Engl J Med. 2019;381(18):1707-1717. doi:10.1056/NEJMoa1907863

38. Breton MD, Kovatchev BP. One year real-world use of the control-IQ advanced hybrid closed-loop technology. Diabetes Technol Ther. 2021;23(9):601-608. doi:10.1089/dia.2021.0097

39. Messer LH, Berget C, Pyle L, et al. Real-world use of a new hybrid closed loop improves glycemic control in youth with type 1 diabetes. Diabetes Technol Ther. 2021. doi:10.1089/dia.2021.0165

40. Breton MD, Kanapka LG, Beck RW, et al. A randomized trial of closed-loop control in children with type 1 diabetes. $N$ Engl $J$ Med. 2020;383(9):836-845. doi:10.1056/NEJMoa2004736

41. Forlenza GP, Buckingham BA, Brown SA, et al. First outpatient evaluation of a tubeless automated insulin delivery system with customizable glucose targets in children and adults with type 1 diabetes. Diabetes Technol Ther. 2021;23(6):410-424. doi:10.1089/dia.2020.0546

42. Brown SA, Forlenza GP, Bode BW, et al. Multicenter trial of a tubeless, on-body automated insulin delivery system with customizable glycemic targets in pediatric and adult participants with type 1 diabetes. Diabetes Care. 2021;44(7):1630-1640. doi:10.2337/dc210172

43. Sherr JL, Buckingham BA, Forlenza GP, et al. Safety and performance of the OmniPod hybrid closed-loop system in adults, adolescents, and children with type 1 diabetes over 5 days under free-living conditions. Diabetes Technol Ther. 2020;22 (3):174-184. doi:10.1089/dia.2019.0286
44. Benhamou PY, Huneker E, Franc S, Doron M, Charpentier G Customization of home closed-loop insulin delivery in adult patients with type 1 diabetes, assisted with structured remote monitoring: the pilot WP7 Diabeloop study. Acta Diabetol. 2018;55(6):549-556. doi:10.1007/s00592-018-1123-1

45. Amadou C, Franc S, Benhamou PY, et al. Diabeloop DBLG1 closed-loop system enables patients with type 1 diabetes to significantly improve their glycemic control in real-life situations without serious adverse events: 6-month follow-up. Diabetes Care. 2021;44(3):844-846. doi:10.2337/dc20-1809

46. Chen NS, Boughton CK, Hartnell S, et al. User engagement with the CamAPS FX hybrid closed-loop app according to age and user characteristics. Diabetes Care. 2021;44(7):e148-e150. doi:10.2337/dc20-2762

47. Tauschmann M, Allen JM, Nagl K, et al. Home use of day-andnight hybrid closed-loop insulin delivery in very young children: a multicenter, 3-week, randomized trial. Diabetes Care. 2019;42 (4):594-600. doi:10.2337/dc18-1881

48. Tauschmann M, Thabit H, Bally L, et al. Closed-loop insulin delivery in suboptimally controlled type 1 diabetes: a multicentre, 12-week randomised trial. Lancet. 2018;392 (10155):1321-1329. doi:10.1016/s0140-6736(18)31947-0

49. Tauschmann M, Allen JM, Wilinska ME, et al. Day-and-night hybrid closed-loop insulin delivery in adolescents with type 1 diabetes: a free-living, randomized clinical trial. Diabetes Care. 2016;39(7):1168-1174. doi:10.2337/dc15-2078

50. Commissariat PV, Boyle CT, Miller KM, et al. Insulin pump use in young children with type 1 diabetes: sociodemographic factors and parent-reported barriers. Diabetes Technol Ther. 2017;19 (6):363-369. doi:10.1089/dia.2016.0375

51. Garmo A, Hörnsten $\AA$, Leksell J. 'The pump was a saviour for me.' Patients' experiences of insulin pump therapy. Diabet Med. 2013;30(6):717-723. doi:10.1111/dme.12155

52. Tanenbaum ML, Adams RN, Hanes SJ, et al. Optimal use of diabetes devices: clinician perspectives on barriers and adherence to device use. J Diabetes Sci Technol. 2017;11(3):484-492. doi:10.1177/1932296816688010

53. Messer LH, Tanenbaum ML, Cook PF, et al. Cost, hassle, and on-body experience: barriers to diabetes device use in adolescents and potential intervention targets. Diabetes Technol Ther. 2020;22 (10):760-767. doi:10.1089/dia.2019.0509

54. Tanenbaum ML, Hanes SJ, Miller KM, Naranjo D, Bensen R, Hood KK. Diabetes device use in adults with type 1 diabetes: barriers to uptake and potential intervention targets. Diabetes Care. 2017;40(2):181-187. doi:10.2337/dc16-1536

55. Musolino G, Dovc K, Boughton CK, et al. Reduced burden of diabetes and improved quality of life: experiences from unrestricted day-and-night hybrid closed-loop use in very young children with type 1 diabetes. Pediatr Diabetes. 2019;20(6):794-799. doi:10.1111/pedi.12872

56. Wong JC, Foster NC, Maahs DM, et al. Real-time continuous glucose monitoring among participants in the T1D exchange clinic registry. Diabetes Care. 2014;37(10):2702-2709. doi:10.2337/dc14-0303

57. Seereiner S, Neeser K, Weber C, et al. Attitudes towards insulin pump therapy among adolescents and young people. Diabetes Technol Ther. 2010;12(1):89-94. doi:10.1089/dia.2009.0080

58. Binek A, Rembierz-Knoll A, Polańska J, Jarosz-Chobot P. Reasons for the discontinuation of therapy of personal insulin pump in children with type 1 diabetes. Pediatr Endocrinol Diabetes Metab. 2016;21(2):65-69. doi:10.18544/pedm21.02.0026

59. de Vries L, Grushka Y, Lebenthal Y, Shalitin S, Phillip M. Factors associated with increased risk of insulin pump discontinuation in pediatric patients with type 1 diabetes. Pediatr Diabetes. 2011;12 (5):506-512. doi:10.1111/j.1399-5448.2010.00701.x 
60. Ritholz MD, Atakov-Castillo A, Beste M, et al. Psychosocial factors associated with use of continuous glucose monitoring. Diabet Med. 2010;27(9):1060-1065. doi:10.1111/j.14645491.2010.03061.x

61. Kubiak T, Mann CG, Barnard KC, Heinemann L. Psychosocial aspects of continuous glucose monitoring: connecting to the patients' experience. $J$ Diabetes Sci Technol. 2016;10 (4):859-863. doi:10.1177/1932296816651450

62. Berg AK, Olsen BS, Thyssen JP, et al. High frequencies of dermatological complications in children using insulin pumps or sensors. Pediatr Diabetes. 2018;19(4):733-740. doi:10.1111/ pedi. 12652

63. Messer LH, Berget C, Beatson C, Polsky S, Forlenza GP. Preserving skin integrity with chronic device use in diabetes. Diabetes Technol Ther. 2018;20(S2):S254-s264. doi:10.1089/ dia.2018.0080

64. Conwell LS, Pope E, Artiles AM, Mohanta A, Daneman A, Daneman D. Dermatological complications of continuous subcutaneous insulin infusion in children and adolescents. J Pediatr. 2008;152(5):622-628. doi:10.1016/j.jpeds.2007.10.006

65. Binder E, Lange O, Edlinger M, et al. Frequency of dermatological side effects of continuous subcutaneous insulin infusion in children and adolescents with type 1 diabetes. Exp Clin Endocrinol Diabetes. 2015;123(4):260-264. doi:10.1055/s-00341394381

66. Schober E, Rami B. Dermatological side effects and complications of continuous subcutaneous insulin infusion in preschool-age and school-age children. Pediatr Diabetes. 2009;10(3):198-201. doi:10.1111/j.1399-5448.2008.00477.x

67. Pfützner J, Hellhammer J, Musholt $P$, et al. Evaluation of dexterity in insulin-treated patients with type 1 and type 2 diabetes mellitus. $J$ Diabetes Sci Technol. 2011;5(1):158-165. doi:10.1177/193229681100500122

68. Pfützner A, Forst T, Niemeyer M, Bailey T. Assessment for ease of use and preference of a new prefilled insulin pen (FlexTouch Degludec U100/U200) versus the SoloSTAR insulin pen by patients with diabetes and healthcare professionals. Expert Opin Drug Deliv. 2014;11 (9):1381-1389. doi:10.1517/17425247.2014.927438

69. Schipper C, Musholt P, Niemeyer M, et al. Patient device assessment evaluation of two insulin injection devices in a mixed cohort of insulin-treated patients with type 1 or type 2 diabetes mellitus. Curr Med Res Opin. 2012;28(8):1297-1303. doi:10.1185/ 03007995.2012.708325

70. Pratley RE, Kanapka LG, Rickels MR, et al. Effect of continuous glucose monitoring on hypoglycemia in older adults with type 1 diabetes: a randomized clinical trial. JAMA. 2020;323 (23):2397-2406. doi:10.1001/jama.2020.6928

71. Gajewska KA, Biesma R, Bennett K, Sreenan S. Barriers and facilitators to accessing insulin pump therapy by adults with type 1 diabetes mellitus: a qualitative study. Acta Diabetol. 2021;58 (1):93-105. doi:10.1007/s00592-020-01595-5

72. Leelarathna L, Choudhary P, Wilmot EG, et al. Hybrid closed-loop therapy: where are we in 2021? Diabetes Obes Metab. 2021;23(3):655-660. doi:10.1111/dom.14273

73. Messer LH, Berget C, Vigers T, et al. Real world hybrid closed-loop discontinuation: predictors and perceptions of youth discontinuing the $670 \mathrm{G}$ system in the first 6 months. Pediatr Diabetes. 2020;21(2):319-327. doi:10.1111/pedi.12971

74. Naranjo D, Suttiratana SC, Iturralde E, et al. What end users and stakeholders want from automated insulin delivery systems. Diabetes Care. 2017;40(11):1453-1461. doi:10.2337/dc17-0400

75. Iturralde E, Tanenbaum ML, Hanes SJ, et al. Expectations and attitudes of individuals with type 1 diabetes after using a hybrid closed loop system. Diabetes Educ. 2017;43(2):223-232. doi: $10.1177 / 0145721717697244$
76. Reidy C, Bracher M, Foster C, Vassilev I, Rogers A. The process of incorporating insulin pumps into the everyday lives of people with Type 1 diabetes: a critical interpretive synthesis. Health Expect. 2018;21(4):714-729. doi:10.1111/hex.12666

77. Borges U, Kubiak T. Continuous glucose monitoring in type 1 diabetes. J Diabetes Sci Technol. 2016;10(3):633-639. doi:10.1177/1932296816634736

78. Kubiak T, Priesterroth L, Barnard-Kelly KD. Psychosocial aspects of diabetes technology. Diabet Med. 2020;37 (3):448-454. doi:10.1111/dme.14234

79. Rubin RR, Borgman SK, Sulik BT. Crossing the technology divide: practical strategies for transitioning patients from multiple daily insulin injections to sensor-augmented pump therapy. Diabetes Educ. 2011;37(Suppl 1):5S-18S; quiz 19S-20S. doi:10.1177/0145721710391107

80. Commissariat PV, Whitehouse AL, Hilliard ME, et al. Sources and valence of information impacting parents' decisions to use diabetes technologies in young children $<8$ years old with type 1 diabetes. Diabetes Technol Ther. 2020;22(9):697-700. doi:10.1 089/dia.2019.0497

81. James S, Perry L, Gallagher R, Lowe J. Diabetes educators: perceived experiences, supports and barriers to use of common diabetes-related technologies. J Diabetes Sci Technol. 2016;10 (5):1115-1121. doi:10.1177/1932296816660326

82. White HD, Goenka N, Furlong NJ, et al. The U.K. service level audit of insulin pump therapy in adults. Diabet Med. 2014;31 (4):412-418. doi:10.1111/dme.12325

83. Lawton J, Kirkham J, Rankin D, et al. Who gains clinical benefit from using insulin pump therapy? A qualitative study of the perceptions and views of health professionals involved in the Relative Effectiveness of Pumps over MDI and Structured Education (REPOSE) trial. Diabet Med. 2016;33(2):243-251. doi: $10.1111 /$ dme. 12879

84. Grunberger G, Abelseth JM, Bailey TS, et al. Consensus statement by the American Association of clinical endocrinologists/American College of Endocrinology insulin pump management task force. Endocr Pract. 2014;20(5):463-489. doi:10.4158/ep14145.Ps

85. Naranjo D, Tanenbaum ML, Iturralde E, Hood KK. Diabetes technology: uptake, outcomes, barriers, and the intersection with distress. J Diabetes Sci Technol. 2016;10(4):852-858. doi:10.11 77/1932296816650900

86. Carlson AL, Martens TW, Johnson L, Criego AB. Continuous glucose monitoring integration for remote diabetes management: virtual diabetes care with case studies. Diabetes Technol Ther. 2021;23(S3):S56-s65. doi:10.1089/dia.2021.0241

87. Kirzhner A, Zornitzki T, Ostrovsky V, Knobler H, Schiller T. Is telemedicine the preferred visit modality in patients with type 1 diabetes? Exp Clin Endocrinol. 2021. doi:10.1055/a-1532-4610

88. Addala A, Auzanneau M, Miller K, et al. A decade of disparities in diabetes technology use and $\mathrm{HbA}(1 \mathrm{c})$ in pediatric type 1 diabetes: a transatlantic comparison. Diabetes Care. 2021;44 (1):133-140. doi:10.2337/dc20-0257

89. Addala A, Suttiratana SC, Wong JJ, et al. Cost considerations for adoption of diabetes technology are pervasive: a qualitative study of persons living with type 1 diabetes and their families. Diabet Med. 2021:e14575. doi:10.1111/dme.14575

90. Roze S, Smith-Palmer J, de Portu S, Delbaere A, de Brouwer B, de Valk HW. Cost-effectiveness of sensor-augmented insulin pump therapy vs continuous subcutaneous insulin infusion in patients with type 1 diabetes in the Netherlands. Clinicoecon Outcomes Res. 2019;11:73-82. doi:10.2147/ceor.S186298

91. Jendle J, Pöhlmann J, de Portu S, Smith-Palmer J, Roze S. Costeffectiveness analysis of the MiniMed 670G hybrid closed-loop system versus continuous subcutaneous insulin infusion for treatment of type 1 diabetes. Diabetes Technol Ther. 2019;21 (3):110-118. doi:10.1089/dia.2018.0328 
92. Gajewska KA, Bennett K, Biesma R, Sreenan S. Low uptake of continuous subcutaneous insulin infusion therapy in people with type 1 diabetes in Ireland: a retrospective cross-sectional study. BMC Endocr Disord. 2020;20(1):92. doi:10.1186/s12902-020-00573-w

93. Danne T, Phillip M, Buckingham BA, et al. ISPAD clinical practice consensus guidelines 2018: insulin treatment in children and adolescents with diabetes. Pediatr Diabetes. 2018;19(Suppl 27):115-135. doi:10.1111/pedi.12718

94. Argento NB, Liu J, Hughes AS, McAuliffe-Fogarty AH. Impact of medicare continuous subcutaneous insulin infusion policies in patients with type 1 diabetes. J Diabetes Sci Technol. 2020;14 (2):257-261. doi:10.1177/1932296819838292

95. Hernandez I, Good CB, Shrank WH, Gellad WF. Trends in medicaid prices, market share, and spending on long-acting insulins, 2006-2018. JAMA. 2019;321(16):1627-1629. doi:10.1001/ jama.2019.2990

96. Tsai D, Flores Garcia J, Fogel JL, Wee CP, Reid MW, Raymond JK. Diabetes technology experiences among latinx and non-latinx youth with type 1 diabetes. J Diabetes Sci Technol. 2021;19322968211029260. doi:10.1177/ 19322968211029260

97. Telo GH, Volkening LK, Butler DA, Laffel LM. Salient characteristics of youth with type 1 diabetes initiating continuous glucose monitoring. Diabetes Technol Ther. 2015;17(6):373-378. doi:10.1089/dia.2014.0290

98. Paris CA, Imperatore G, Klingensmith G, et al. Predictors of insulin regimens and impact on outcomes in youth with type 1 diabetes: the SEARCH for Diabetes in Youth study. J Pediatr. 2009;155(2):183-9.e1. doi:10.1016/j.jpeds.2009.01.063

99. Miller KM, Beck RW, Foster NC, Maahs DM. HbA1c levels in type 1 diabetes from early childhood to older adults: a deeper dive into the influence of technology and socioeconomic status on HbA1c in the T1D exchange clinic registry findings. Diabetes Technol Ther. 2020;22(9):645-650. doi:10.1089/dia.2019.0393

100. O'Connor MR, Carlin K, Coker T, Zierler B, Pihoker C. Disparities in insulin pump therapy persist in youth with type 1 diabetes despite rising overall pump use rates. J Pediatr Nurs. 2019;44:16-21. doi:10.1016/j.pedn.2018.10.005

101. Willi SM, Miller KM, DiMeglio LA, et al. Racial-ethnic disparities in management and outcomes among children with type 1 diabetes. Pediatrics. 2015;135(3):424-434. doi:10.1542/ peds.2014-1774

102. Hall WJ, Chapman MV, Lee KM, et al. Implicit racial/ethnic bias among health care professionals and its influence on health care outcomes: a systematic review. Am J Public Health. 2015;105 (12):e60-76. doi:10.2105/ajph.2015.302903

103. Addala A, Hanes S, Naranjo D, Maahs DM, Hood KK. Provider implicit bias impacts pediatric type 1 diabetes technology recommendations in the United States: findings from The Gatekeeper Study. J Diabetes Sci Technol. 2021:19322968211006476. doi:10.1177/19322968211006476

104. Polonsky WH, Hessler D. What are the quality of life-related benefits and losses associated with real-time continuous glucose monitoring? A survey of current users. Diabetes Technol Ther. 2013;15(4):295-301. doi:10.1089/dia.2012.0298

105. Polonsky WH, Hessler D, Ruedy KJ, Beck RW. The impact of continuous glucose monitoring on markers of quality of life in adults with type 1 diabetes: further findings from the DIAMOND randomized clinical trial. Diabetes Care. 2017;40(6):736-741. doi:10.2337/dc17-0133

106. Beck RW, Lawrence JM, Laffel L, et al. Quality-of-life measures in children and adults with type 1 diabetes: Juvenile diabetes research foundation continuous glucose monitoring randomized trial. Diabetes Care. 2010;33(10):2175-2177. doi:10.2337/dc100331
107. Markowitz JT, Pratt K, Aggarwal J, Volkening LK, Laffel LM. Psychosocial correlates of continuous glucose monitoring use in youth and adults with type 1 diabetes and parents of youth. Diabetes Technol Ther. 2012;14(6):523-526. doi:10.1089/dia.2011.0201

108. Papadakis JL, Anderson LM, Garza K, et al. Psychosocial aspects of diabetes technology use: the child and family perspective. Endocrinol Metab Clin North Am. 2020;49(1):127-141. doi:10.1016/j.ecl.2019.10.004

109. Mueller-Godeffroy E, Vonthein R, Ludwig-Seibold C, et al. Psychosocial benefits of insulin pump therapy in children with diabetes type 1 and their families: the pumpkin multicenter randomized controlled trial. Pediatr Diabetes. 2018;19 (8):1471-1480. doi:10.1111/pedi.12777

110. McGill DE, Volkening LK, Pober DM, Muir AB, Young-Hyman DL, Laffel LM. Depressive symptoms at critical times in youth with type 1 diabetes: following type 1 diabetes diagnosis and insulin pump initiation. J Adolesc Health. 2018;62(2):219-225. doi:10.1016/j.jadohealth.2017.09.017

111. Wong JC, Dolan LM, Yang TT, Hood KK. Insulin pump use and glycemic control in adolescents with type 1 diabetes: predictors of change in method of insulin delivery across two years. Pediatr Diabetes. 2015;16(8):592-599. doi:10.1111/pedi.12221

112. Wong JC, Boyle C, DiMeglio LA, et al. Evaluation of pump discontinuation and associated factors in the T1D exchange clinic registry. $J$ Diabetes Sci Technol. 2017;11(2):224-232. doi:10.1177/1932296816663963

113. Mauras N, Beck R, Xing D, et al. A randomized clinical trial to assess the efficacy and safety of real-time continuous glucose monitoring in the management of type 1 diabetes in young children aged 4 to $<10$ years. Diabetes Care. 2012;35(2):204-210. doi:10.2337/dc11-1746

114. Heller S, White D, Lee E, et al. A cluster randomised trial, cost-effectiveness analysis and psychosocial evaluation of insulin pump therapy compared with multiple injections during flexible intensive insulin therapy for type 1 diabetes: the REPOSE trial. Health Technol Assess. 2017;21(20):1-278. doi:10.3310/hta21200

115. Rubin RR, Peyrot M. Health-related quality of life and treatment satisfaction in the sensor-augmented pump therapy for A1C reduction 3 (STAR 3) trial. Diabetes Technol Ther. 2012;14 (2):143-151. doi:10.1089/dia.2011.0162

116. Cemeroglu AP, Stone R, Kleis L, Racine MS, Postellon DC, Wood MA. Use of a real-time continuous glucose monitoring system in children and young adults on insulin pump therapy: patients' and caregivers' perception of benefit. Pediatr Diabetes. 2010;11(3):182-187. doi:10.1111/j.1399-5448.2009.00549.x

117. Nosova EV, O’Malley G, Dassau E, Levy CJ. Leveraging technology for the treatment of type 1 diabetes in pregnancy: a review of past, current, and future therapeutic tools. J Diabetes. 2020;12 (10):714-732. doi:10.1111/1753-0407.13030

118. Breton MD, Chernavvsky DR, Forlenza GP, et al. Closed loop control during intense prolonged outdoor exercise in adolescents with type 1 diabetes: the artificial pancreas ski study. Diabetes Care. 2017;40(12):1644-1650. doi:10.2337/dc17-0883

119. Ekhlaspour L, Forlenza GP, Chernavvsky D, et al. Closed loop control in adolescents and children during winter sports: use of the Tandem Control-IQ AP System. Pediatr Diabetes. 2019. doi:10.1111/pedi.12867

120. Lal RA, Hsu L, Zhang J, Schøndorff PK, Heschel M, Buckingham B. Longevity of the novel ConvaTec infusion set with Lantern technology. Diabetes Obes Metab. 2021;23 (8):1973-1977. doi:10.1111/dom.14395

121. Rankin D, Kimbell B, Allen JM, et al. Adolescents' experiences of using a smartphone application hosting a closed-loop algorithm to manage type 1 diabetes in everyday life: qualitative study. J Diabetes Sci Technol. 2021;15(5):1042-1051. doi:10.1177/ 1932296821994201 
122. Aleppo G, Parkin CG, Carlson A, et al. Lost in translation. A disconnect between the science and medicare coverage criteria for continuous subcutaneous insulin infusion (CSII). Diabetes Technol Ther. 2021;23(10):715-725. doi:10.1089/dia.2021.0196
123. Galindo RJ, Parkin CG, Aleppo G, et al. What's wrong with this picture? A critical review of current centers for medicare \& medicaid services coverage criteria for continuous glucose monitoring. Diabetes Technol Ther. 2021;23(9):652-660. doi:10.1089/dia.2021.0107

\section{Publish your work in this journal}

Medical Devices: Evidence and Research is an international, peerreviewed, open access journal that focuses on the evidence, technology, research, and expert opinion supporting the use and application of medical devices in the diagnosis, monitoring, treatment and management of clinical conditions and physiological processes. The identification of novel devices and optimal use of existing devices which will lead to improved clinical outcomes and more effective patient management and safety is a key feature of the journal The manuscript management system is completely online and includes a very quick and fair peer-review system. Visit http:// www.dovepress.com/testimonials.php to read real quotes from published authors.

Submit your manuscript here: https://www.dovepress.com/medical-devices-evidence-and-research-journal 